\title{
Dielektrične karakteristike $\mathrm{Er}_{2} \mathrm{O}_{3}$ dopirane $\mathrm{BaTiO}_{3}$ keramike
}

\author{
MILOŠ D. ĐORĐEVIĆ, Univerzitet u Nišu, \\ Elektronski fakultet, Niš \\ MILOŠ B. MARJANOVIĆ, Univerzitet u Nišu, \\ Elektronski fakultet, $\mathrm{Niš}$ \\ VESNA V. PAUNOVIĆ, Univerzitet u Nišu, \\ Elektronski fakultet, Niš
}

\author{
Originalni naučni rad \\ UDC: 666.3 .017 \\ DOI: 10.5937/tehnika1504577D
}

U radu su ispitivane mikrostrukturne i dielektrične karakteristike Er dopirane $\mathrm{BaTiO}_{3}$ keramike. Koncentracija korišćenog dopanata, $\mathrm{Er}_{2} \mathrm{O}_{3}$, u ispitivanim uzorcima kretala se od 0.01 do 1.0 at\%. Korišćena je konvencionalna metoda za dobijanje modifikovane $\mathrm{BaTiO}_{3}$ keramike, sinterovanjem u čvrstoj fazi na temperaturama od $1320^{\circ}, 1350^{\circ}$ i $1380^{\circ} \mathrm{C}$ u trajanju od 4 h. SEM analiza Er/BaTiO dopirane keramike pokazala je da je za uzorke dopirane manjom koncentracijom aditiva (0.01 i 0.1at\%) karakteristična homogena mikrostruktura sa veličinom zrna od 10 do $25 \mu \mathrm{m}$. Za uzorke dopirane većom koncentracijom aditiva (0.5 i 1.0 at\%) karakteristična veličina zrna kretala se od 7 do $15 \mu m$. Dielektrične karakteristike merene su u frekventnom intervalu od $20 \mathrm{~Hz}$ do $1 \mathrm{MHz}$ na sobnoj temperaturi. Za uzorke dopirane sa 0.01 at\% Er i sinterovane na $1380^{\circ} \mathrm{C}$ dielektrična konstanta na sobnoj temperature je iznosila $\varepsilon_{r}=947$. Za uzorke dopirane istom koncentracijom Er sinterovane na temperaturi $1320{ }^{\circ} \mathrm{C}$ utvrđena je niža vrednost dielektrične konstante $\left(\varepsilon_{r}=551\right)$. Takođe sa povećanjem temperature sinterovanja dielektrična konstanta uzoraka se povećavala tako da je navjiša vrednost izmerena za uzorke sinterovane na 1380 ${ }^{\circ} \mathrm{C}$. Za sve ispitivane uzorke dopirane Er merena je i specifična električna otpornost i najveća vrednost specifične otopornosti dobijena je za uzorke sinterovane na temperaturi od $1320^{\circ} \mathrm{C}$.

Ključne reči: $\mathrm{BaTiO}_{3}$, sinterovanje, mikrostruktura dielektrične karakteristike

\section{UVOD}

Modifikovana $\mathrm{BaTiO}_{3}$ keramika dopirana različitim aditivima/dopantima je jedna od najznačajnijih grupa funkcionalnih elektronskih keramičkih materijala koja se zbog svojih izuzetnih električnih, feroelektričnih i piezoelektričnih karakteristika koristi za dobijanje elektronskih komponenata kao što su višeslojni kondenzatori, PTC termistori, piezoelektrični senzori, komponente za konverziju energije, elektrooptičke komponente, ultrazvučni pretvarači, radio i komunikacioni filtri $[1,2]$.

Da bi se pripremila $\mathrm{BaTiO}_{3}$ keramika koja ima veliku vrednost relativne dielektrične konstante potrebno je ostvariti optimalnu gustinu, homogenu mikrostrukturu i uniformnu raspodelu dopanata i aditiva $[3$, 4].

S obzirom na perovskitnu $\mathrm{ABO}_{3}$ strukturu $\mathrm{BaTiO}_{3}$

Adresa autora: Miloš Đorđević, Univerzitet u Nišu, Elektronski fakultet, Niš, Aleksandra Medvedeva 14

Rad primljen: 11.03.2015.

Rad prihvaćen: 01.07.2015. materijala, a u zavisnosti od radijusa jona, joni dopanata se mogu ugraditi na mesta $\mathrm{A}\left(\mathrm{Ba}^{2+}\right)$ ili $\mathrm{B}\left(\mathrm{Ti}^{4+}\right)$ jona, uslovljavajući tako dielektrična ili poluprovodna svojstva keramike. Kako su radijusi jona trovalentnih katjona retkih zemalja $\left(\mathrm{Er}^{3+}, \mathrm{Ho}^{3+}, \mathrm{Dy}^{3+}, \mathrm{Yb}^{3+}\right)$ po veličini između jonskih radijusa $\mathrm{Ba}^{2+}$ ili $\mathrm{Ti}^{4+}$ jona, oni mogu da zauzmu $\left(\mathrm{Ba}^{2+}\right)$ ili $\left(\mathrm{Ti}^{4+}\right)$ položaje u perovskitoj strukturi $\mathrm{BaTiO}_{3}$ [5-7].

Pri niskim koncentracijama Er dolazi do supstitucije $\mathrm{Ba}^{2+}$ jona $\mathrm{i}$ do formiranja čvrstih rastvora. Pri većim koncentracijama aditiva iznad 1.0 at $\%$ može doći do supstitucije $\mathrm{Ba}^{2+}$ ili $\mathrm{Ti}^{4+}$ jona pri čemu je specifična električna otpornost uzorka veoma visoka, reda veličine $10^{8} \Omega \mathrm{m}$. Supstitucija $\mathrm{Er}^{3+}$ na mesto $\mathrm{Ba}^{2+}$ jona zahteva formiranje negatvno naelektrisanih defekata radi očuvanja elektroneutralnosti [8].

$\mathrm{U}$ ovom radu ispitivan je uticaj koncentracije aditiva i temperature sinterovanja na mikrostrukturna $\mathrm{i}$ dielektrična svojstva Er dopirane $\mathrm{BaTiO}_{3}$ keramike. Mikrostrukturne karakteristike ispitivane su skenirajućim elektronskim mikroskopom (SEM), a dielektrična konstanta i specifična otpornost uzoraka određivane su u frekventnom intervalu od $20 \mathrm{~Hz}$ do $1 \mathrm{MHz}$. 


\section{EKSPERIMENTALNI DEO}

$\mathrm{U}$ ovom radu proučavana je $\mathrm{BaTiO}_{3}$ keramika dopirana sa $0.01,0.1,0.5$ i 1.0 at $\% \mathrm{Er}_{2} \mathrm{O}_{3}$. Uzorci su pripremljeni konvencionalnom metodom sinterovanja u čvrstoj fazi polazeći od čistih oksidnih prahova $\mathrm{BaTiO}_{3}$ (Rhone Poulenc $\left.\mathrm{Ba} / \mathrm{Ti}=0.996 \pm 0.004\right)$ i $\mathrm{Er}_{2} \mathrm{O}_{3}$ (Fluka chemika). Prahovi su mešani u izopropil alkoholu, sušeni i presovani u diskove prečnika $10 \mathrm{~mm}$ i 2 $\mathrm{mm}$ debljine, pri pritisku od $120 \mathrm{MPa}$. Presovani uzorci su sinterovani $\mathrm{u}$ atmosferi vazduha na temperaturi $1320^{\circ}, 1350^{\circ}$ i $1380^{\circ} \mathrm{C}$ u trajanju od četiri sata. Mikrostrukturna ispitivanja i kompozicioni sastav keramike analizirani su pomoću skenirajućeg elektronskog mikroskopa SEM JEOL-5300 koji je opremljen i energijsko disperzivnim spektrometrom (EDS). Pre merenja dielektričnih karakteristika na uzorke je naneta srebrna pasta. Dielektrične karakteristike uzoraka su izračunate na osnovu merenja kapacitivnosti u frekventnom opsegu od $20 \mathrm{~Hz}$ do $1 \mathrm{MHz}$ pomoću LCR-metra Agilent 4284A.

\section{REZULTATI I DISKUSIJA}

\subsection{Mikrostrukturna ispitivanja}

Relativna gustina Erbium dopirane keramike kretala se od 83 do $88 \%$ od teorijske gustine (TG). Gustina uzoraka se povećavala sa povećanjem temperature sinterovanja i opadala sa povećanjem koncentracije aditiva tako da je najveća gustina izmerena za uzorke dopirane sa 0.01 at $\%$ aditiva i sinterovane na $1380^{\circ} \mathrm{C}$. Uzorke $\mathrm{BaTiO}_{3}$ keramike dopirane $\mathrm{Er}_{2} \mathrm{O}_{3}$ karakterišu poligonalna zrna. Za manje koncentracije $\operatorname{Er}(0.01 \mathrm{at} \%$ Er) karakterističan je abnormalni rast zrna i veličina zrna koja se kretala od 10 do $25 \mu \mathrm{m}$ (Slika 1a i 1c). Sa povećanjem koncentracije dopanata dolazi do smanjenja srednje veličine zrna (slika 1 b i 1d) i ona se za uzorke dopirane sa 1.0 at $\%$ aditiva i sinterovane na $1380{ }^{\circ} \mathrm{C}$ kretala od 7 do $15 \mu \mathrm{m}$.

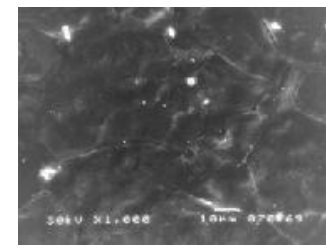

(a)

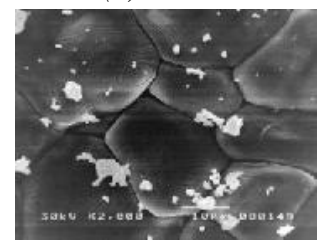

(c)

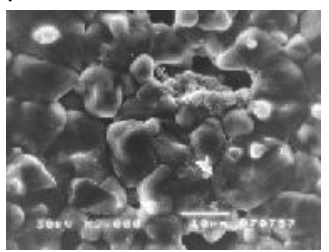

(b)

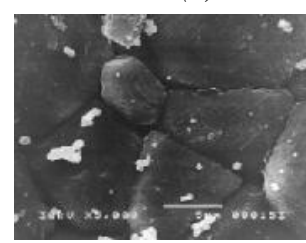

(d)
Slika 1 - SEM mikrostruktura Er dopirane $\mathrm{BaTiO}_{3}$ keramike a) $0.01 \mathrm{i} \mathrm{b}) 1.0 \mathrm{at} \% \mathrm{Er}$, Tsin $=1320^{\circ} \mathrm{C}$ ic) $0.01 \mathrm{id}$ ) $1.0 \mathrm{at} \% \mathrm{Er}, \mathrm{Tsin}=1380 \mathrm{C}$

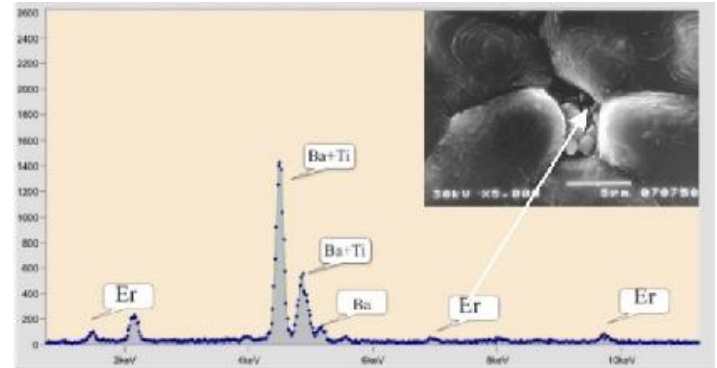

Slika 2 - EDS spektar 1.0 at \% Er dopirane $\mathrm{BaTiO}_{3}$ keramike

EDS analiza uzoraka dopiranih manjom koncentracijom aditiva (0.01 i 0.1 at\% Er) uzeta sa različitih oblasti jednog uzorka, pokazala je uniformnu raspodelu Er. Kod uzoraka dopiranih većom koncentracijom aditiva (1.0 at\% Er) došlo je do nagomilavanje Er u oblasti između zrna i EDS analiza pokazala je postojanje oblasti bogatih Er (slika 2). Potrebno je napomenuti da EDS analiza ne može detektovati koncentracije elemenata manje od 1.0 at $\%$ izuzev kada dolazi do nehomogene distribucije ili segregacije aditiva.

\subsection{Električne karakteristike}

Uticaj aditiva i mikrostrukture na dielektričnu konstantu dopirane $\mathrm{BaTiO}_{3}$ keramike proučavan je prateći promene dielektrične konstante sa frekvencijom (slika 3).

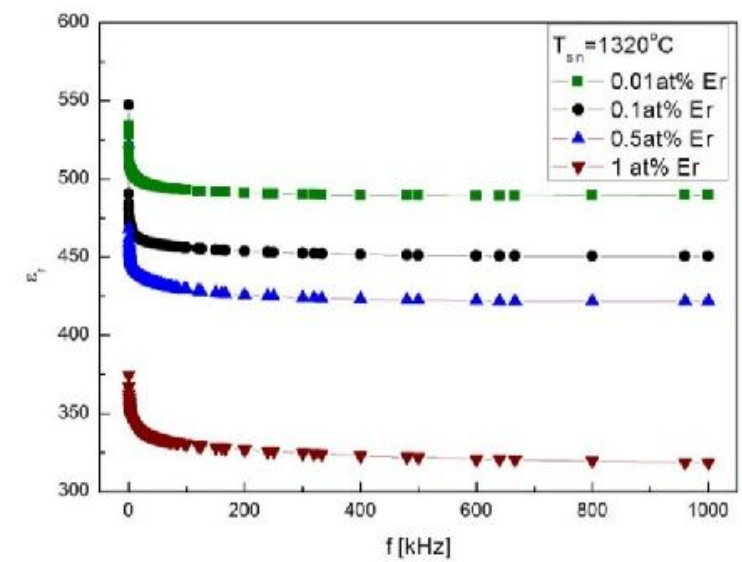

Slika 3 - Dielektrična konstanta dopirane $\mathrm{BaTiO}_{3}$ keramike $u$ funkciji frekvencije $z a$ $T \sin =1320^{\circ} \mathrm{C}$

Karakteristično za dielektričnu konstantu ispitivanih uzoraka je da opada sa povećanjem koncentracije dopanata. Najviše vrednosti $\varepsilon_{r}$ izmerene su za najnižu koncentraciju aditiva od 0.01 at $\%$. Takođe, dielektrična konstanta opada sa povećanjem frekvencije i nakon viših početnih vrednosti na nižim frekvencijama, opada i postiže skoro konstantnu vrednost za frekvencije iznad $20 \mathrm{kHz}$.

$\mathrm{Na}$ slici 3. prikazana je dielektrična konstanta za uzorke sinterovane na temperaturi od $1320^{\circ} \mathrm{C}$. Najviša 
vrednost $\left(\varepsilon_{\mathrm{r}}=547\right)$ izmerena je za uzorke dopirane sa 0.01 at $\%$, a najnižu vrednost $\left(\varepsilon_{\mathrm{r}}=374\right)$ za uzorke dopirane sa 1.0 at $\%$ Er.

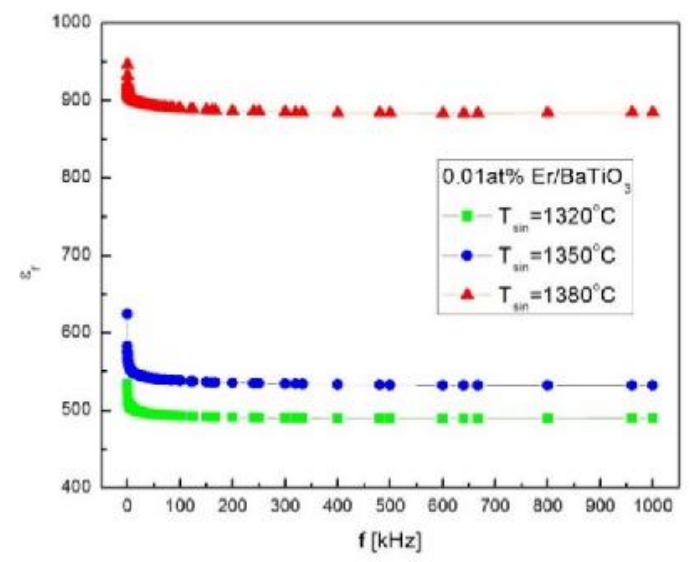

Slika 4 - Dielektrična konstanta 0.01 at\% Er dopirane $\mathrm{BaTiO}_{3}$ keramike u funkciji frekvencije za različite temperature sinterovanja

Takođe, dielektrična konstanta ispitivanih uzoraka raste sa povećanjem temperature sinterovanja (slika 4). Kod uzoraka dopiranih sa 0.01 at $\%$ Er dielektrična konstanta je najviša za uzorke sinterovane na $1380{ }^{\circ} \mathrm{C}$ $\left(\varepsilon_{\mathrm{r}}=956\right)$, a najmanja $\left(\varepsilon_{\mathrm{r}}=551\right)$ za uzorke sinterovane na temperaturi od $1320^{\circ} \mathrm{C}$. Ovakve vrednosti dielektrične konstante su u saglasnosti sa gustinom ispitivane keramike jer je za keramiku sa najvećom gustinom izmerena i najviša vrednost dielektrične konstante.

Proučavana je i promena specifične električne otpornosti kao i promena dielektrične konstante sa promenom frekvencije. Uočeno je da nakon viših početnih vrednosti na niskoj frekvenciji, specifična električna otpornost opada sa povećanjem frekvencije i postaje skoro konstantna na frekvencijama višim od $500 \mathrm{kHz}$. Sa povećanjem temperature sinterovanja specifična električna otpornost opada tako da su najviše vrednosti izmerene kod keramike sinterovane na $1320^{\circ} \mathrm{C}$ (slika $5)$.

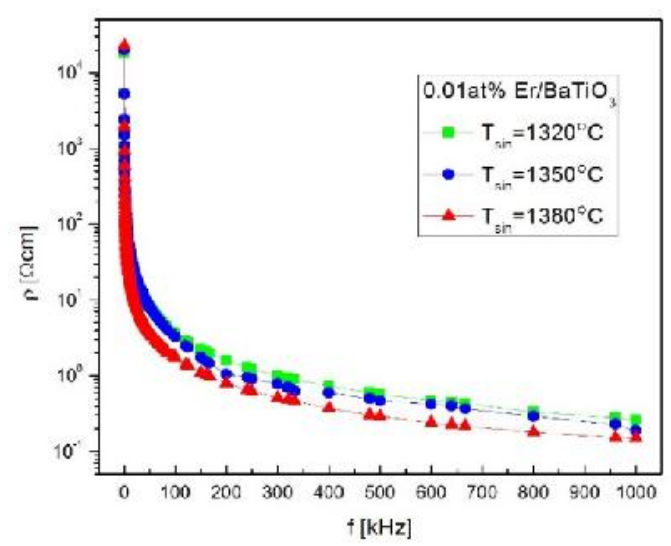

Slika 5 - Specifična otpornost 0.01 at \% Er dopirane $\mathrm{BaTiO}_{3}$ keramike u funkciji frekvencije za različite temperature sinterovanja
Vrednosti specifične električne otpornosti kreću se od $10^{4} \Omega \mathrm{m}$ do $10^{6} \Omega \mathrm{m}$. Smatra se da je jonski kompenzacioni mehanizam dominantan $\mathrm{kod} \mathrm{Er} / \mathrm{BaTiO}_{3}$ dopiranih uzoraka i zbog nemogućnosti pokretljivosti katjonskih vakancija na sobnoj temperaturi i niskim frekvencijama dopirani uzorci su izolatori. Takođe, kod uzoraka sa sitnozrnom mikrostrukturom (uzorci sa većom koncentracijom aditiva) izolaciona svojstva granice zrna su uporediva sa veličinom zrna pa je i otpornost kod njih veća.

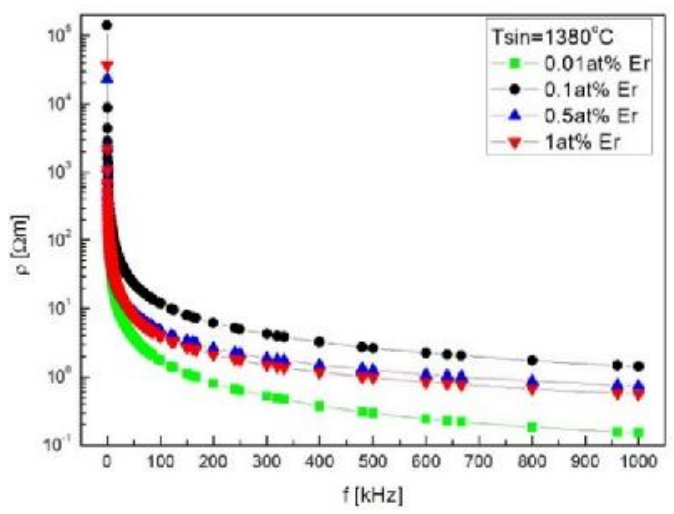

Slika 6 - Specifična otpornost dopirane $\mathrm{BaTiO}_{3}$ keramike u funkciji frekvencije za razlicite koncentracije $\operatorname{Er}\left(T \sin =1380{ }^{\circ} \mathrm{C}\right)$

Promena specifične otpornosti kod merenih uzoraka različitih koncentracija (od 0.01 at $\%$ do 1.0 at $\%$ Er) sinterovanih na istoj temperaturi $\left(\mathrm{T}_{\sin }=1380^{\circ} \mathrm{C}\right)$, prikazana je na slici 6 .

Utvrđeno je da najveću vrednost specifične otpornosti ima uzorak sa koncentracijom aditiva od 0.1 at $\%$, $\left(\rho=10^{6} \Omega \mathrm{m}\right)$ dok najnižu vrednost ima uzorak sa koncentracijom aditiva od 0.01 at $\%$.

Takođe merene su vrednosti otpornosti (realnog dela impedanse) i reaktanse (imaginarnog dela impedanse). Na osnovu merenih rezultata konstruisana je zavisnost imaginarnog dela impedanse u odnosu na realni delo (slika 7). Merena AC karakteristika impedanse u kompleksnoj ravni za sve ispitivane uzorke omogućava određivanje parametara ekvivalentnog kola [9] što će biti cilj daljeg istraživanja i rada.

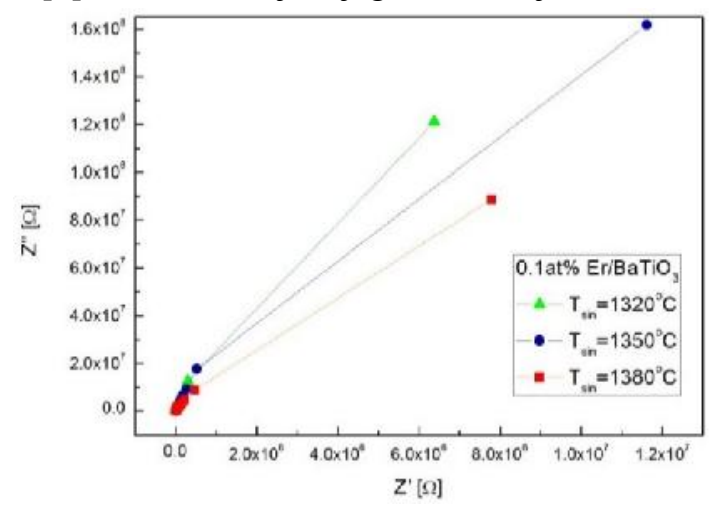

Slika 7 - Zavisnost reaktanse u odnosu na otpornost 


\section{ZAKLJUČAK}

U radu su prikazana rezultati ispitivanja mikrostrukturnih i dielektričnih karakteristika $\mathrm{Er}_{2} \mathrm{O}_{3}$ dopirane $\mathrm{BaTiO}_{3}$ keramike. Pri manjim koncentracijama aditiva ovu keramiku karakteriše abnormalni rast zrna i veličina zrna koja se kretala od 10 do $25 \mu \mathrm{m}$ za manje koncentracije aditiva $(0.01$ at $\%$ Er). Za više koncentracije aditiva ( 0.5 at $\%$ Er) veličina zrna kretala se od 7 do $15 \mu \mathrm{m}$. Najveću dielektričnu konstantu na sobnoj temperaturi i najveću promenu dielektrične konstante sa frekvencijom pokazuju uzorci sa najmanjom koncentracijom aditiva. Dielektrična konstanta 0.01 at $\%$ Er dopirane $\mathrm{BaTiO}_{3}$ keramike sinterovane na $1380{ }^{\circ} \mathrm{C}$ iznosi $\varepsilon_{\mathrm{r}}=956$.

Specifična električna otpornost opada sa povećanjem temperature sinterovanja tako da je najveća specifična otpornost izmerena za uzorke sinterovane na $1320^{\circ} \mathrm{C}$. Najveću promenu specifične elktrične otpornosti sa sa frekvencijom pokazuju mereni uzorci sa najmanjom koncentracijom aditiva $(0.01 \mathrm{at} \% \mathrm{Er})$. Kod uzoraka sinterovanih na $1380{ }^{\circ} \mathrm{C}$ najveću vrednost specifične otpornosti ima uzorak sa koncentracijom aditiva od 0.1 at $\%$ Er.

\section{ZAHVALNOST}

Istraživanja su deo projekata TR-33035 i OI172057. Autori se zahvaljuju finansiskoj podršci Ministarstva prosvete, nauke i tehnološkog razvoja Republike Srbije.

\section{LITERATURA}

[1] Pithan C, Hennings D, Waser R, International Journal of Applied Ceramic Technology 2 1, p.1-14, 2005.

[2] Kuo D. H, Wang C. H, Tsai W. P, Ceramics International 32 , p.1-5, 2006.

[3] Makovec D, Samardžija Z, Drofenik M, J. Am. Ceram. Soc. 87 [7], p.1324-1329, 2004.

[4] Paunovic V, Zivkovic Lj, Mitic V, Science of sintering 42 p.69-79, 2010.

[5] Kishi H, Kohzu N, Sugino J, Ohsato H, Iguchi Y, Okuda T, J. E. Ceram. Soc. 19, p.1043-1046, 1999.

[6] Park K. J, Kim C. H., Yoon Y. J, Song S. M, Kim Y. T, Hur K. H, J. E. Ceram. Soc. 29, 1735-1741, 2009.

[7] Mitic V, Nikolic Z, Pavlovic V, Paunovic V, Miljkovic M, Jordovic B, Zivkovic Lj, J. Am. Ceram. Soc. 93 [1], p.132-137, 2010.

[8] Kishi V, Kohzu V, Iguchi V, Sugino V, Kato V, Ohasato H, Okuda T, J. E. Ceram. Soc. 21 p.1643$1647,2001$.

[9] Mančić D, Paunović V, Primena impedansne spektroskopije za električnu karakterizaciju La dopirane $\mathrm{BaTiO}_{3}$ keramike, Elektronski fakultet, Niš, 2012, p. 47.

\section{SUMMARY}

\section{DIELECTRIC PROPERTIES OF $\mathrm{ER}_{2} \mathrm{O}_{3}$ DOPED BATIO $_{3} \mathrm{CERAMICS}$}

In this paper, the microstructure and dielectric properties of Er-doped $\mathrm{BaTiO}_{3}$ ceramics were investigated. The concentrations of dopant, $\mathrm{Er}_{2} \mathrm{O}_{3}$, in the tested samples were ranged from 0.01 to $1.0 a \mathrm{t} \%$ Er. Conventional solid state reaction was used to obtain modified $\mathrm{BaTiO}_{3}$ ceramics. The samples were sintered at temperatures of $1320^{\circ}, 1350^{\circ}$ and $1380^{\circ} \mathrm{C}$ for 4 hours. SEM analysis of Er/BaTiO $O_{3}$ doped ceramic showed, that samples doped with a smaller concentration of additive (0.01 and 0.1 at\%) characterized a homogeneous microstructure with a grain size from 10 to $25 \mu \mathrm{m}$. For samples doped with a larger concentration of additives (0.5 and 1.0 at\%) characteristic grain size ranged from 7 to 15 $\mu \mathrm{m}$. Dielectric properties were measured in the frequency range of $20 \mathrm{~Hz}$ to $1 \mathrm{MHz}$ at room temperature. Sample doped with Er $0.01 \mathrm{at} \%$, and sintered at $1380^{\circ} \mathrm{C}$ is characterized with a relatively high value of dielectric constant $\left(\varepsilon_{r}=947\right)$ at room temperature. For samples doped with the same concentration of Er and sintered at $1320{ }^{\circ} \mathrm{C}$ temperature characteristic is a lower value of the dielectric constant $\left(\varepsilon_{r}=551\right)$. With the increase of sintering temperature, the dielectric constant of the samples increased, and the highest value were measured for samples sintered at $1380^{\circ} \mathrm{C}$. Also, for all investigated samples were measured resistivity and the highest values of electrical resistivity was obtained for samples sintered at temperatures of $1320^{\circ} \mathrm{C}$.

Key words: $\mathrm{BaTiO}_{3}$, sintering, microstructure, dielectric characteristics 